\title{
The Analysis on Multidimensional Transformation Theory in College Translation Teaching
}

\author{
Man Zhai \\ School of Foreign Languages \\ Jilin Business and Technology College \\ Changchun, China
}

\begin{abstract}
Eco-translatology exercises its inventive mind and adopts an unconventional approach to guide translation with a harmonious and multidimensional perspective and a new researching paradigm. To analyze the college translation course from eco-translatology perspective and decode it from the dimensions of linguistics, culture and communication and the level of choice and adaption. The emergence of eco-translatology not only injects vitality into the current translation theory research, but also provides theoretical support for the new model of college English translation teaching, effectively the status quo of students' weak initiative and poor translation ability in translation teaching. This paper will provide an analysis and necessities on applying multidimensional transformation theory to college English translation teaching from the theoretical principles and practical aspects of eco-translatology.
\end{abstract}

Keywords-eco-translatology; college English translating course; teaching mode; multi-dimensional adjustment; selection

\section{INTRODUCTION}

Under the background of globalization, with the deepening of opening up to the outside world, compound translation talents have become an important bridge for cultural exchanges between China and foreign countries. This puts forward higher requirements for translation teaching for non-English majors, but college English translation teaching has long been at the edge of English translation teaching researches. Most of the domestic researches focus on the comparison between "translation teaching" and "teaching translation", as well as the discussion of the current situation of college English translation teaching, teaching methods, teaching process and curriculum provision. Sun Jing explained the problems existing in the teaching of college English translation in China in terms of teaching system, teachers' theoretical literacy and students' translation ability. It not only drew on the experience of the rule of "natural selection, survival of the fittest" by Darwin, but also inherited Chinese traditional philosophical ideas of "harmony of man with nature" [1] and "person-oriented" in ancient times.

Zhang Hairui proposed five strategies to improve the syllabus, reform the content of teaching materials, change the teaching modes, strengthen the construction of teaching staff and improve students' translation ability according to the existing problems. In short, the predecessors' research on college English translation teaching mostly focuses on the current situation and development direction, and few scholars

This is the research findings of Program the application and research of Eco- translatology over college translation courses supported by the high educational institute of Jilin province, program number is JGJX2018D120 introduced systematic theory to analyze.

\section{THE ORIGIN AND INTERPRETATION OF MULTIDIMENSIONAL TRANSFORMATION THEORY}

\section{A. The Concept of Eco-translatology}

Throughout the domestic researches on translation teaching from the perspective of eco-translatology, mainly for students in English majors, it ignores the translation teaching of nonEnglish majors with a large number of students. At the same time, the discussion on how ecological translation works on translation teaching is mostly at the theory level and it has not been indicated through teaching cases or empirical researches. For this reason, it can easily lead to the disconnection between the theory of eco-translatology and the practice of translation teaching.

The eco-translatology is a new translation theory proposed by Professor Hu Gengshen of Tsinghua University in 2001. It is the first translation theory proposed in China. The development of eco-translatology can be divided into two stages: 2001-2009 is the initial stage, which is mainly represented by the put forward and construction of the theory. It is mainly proposed by Professor Hu Gengshen, so the construction is mainly carried out by Professor Hu Gengshen. Since 2009, it has been a comprehensive development stage, and theoretical research gradually deepens and becomes mature and applied.

1) The linguistics dimension: The production of translation can be roughly divided into two stages from the perspective of linguistics equality over translation: in the first stage, the emphasis is on the selection of translators by the translational eco-environment with the original text as a typical element, and this stage can also be regarded as the translator's adaptation to the translational eco-environment; [2] in the second stage, the focus is put on the selection of the translation by the translational adaption and selection with the translator as a typical element. In other words, the second stage is the translator's translation.

2) The cultural dimension: The cultural status of the source language and the social needs of the translated language also influence the choice of in-translating and out-translating. The cultural variances caused by the imbalance of political and economic development make the translation exhibit a one-way tilt state. The translation books account for a large proportion in the underprivileged culture market, while the privileged cultures are often disdained to translate weak cultures, so its 
small amount of translation books are also exotic texts that cater to western readers' tastes and meet western values and aesthetics. [3] Therefore, the difference in the cultural status of the source language culture and the translated language culture is also an important factor affecting the flow of translation. Whether the translator chooses to translate or not should also take the social needs of the translated language into consideration. Only when the selection and translation of the translated version meet the social needs of the target language, the translation can be recognized by the target readers, and can indeed achieve the purpose of the translation.

3) The communicational dimension: This theory stresses the achievement of the communicational goal and employs the principles of "natural selection" and "survival of the fittest" in Darwin's theory of evolution as reference. Based on the perspective of ecological holism, it proposes the theory of "translation as adaptation and selection" and re-defines the translation: translation is "the selection made by translators to adapt to the translational eco-environment”, and the core point is "translator-centered", and it also elaborates the translation process, translation principles, translation methods, and translation value standards, and puts forward a series of concepts, such as the "ecological rationality", "translating for something”, and "translational eco-environment”, “ex-post punishment”. [4]

\section{B. The Adaption and Selection}

By using the basic principles and ideas of Darwin's theory of evolution to interpret the phenomena and problems in translation, adaption and selection in eco-translatology not only broadens the perspective of translation research, but also provides the theoretical basis for some unexplained translation phenomena. [5] The theory of translation as adaptation and selection is one of its core concepts. It is believed in the ecotranslatology that translation is the adapting activity of the translators to the translational eco-environment. The translational eco-environment refers to the world presented by the original text, the original language and the translated language, that is, the whole world of the language, communication, culture and society, and the overall of the interconnected interaction of the author, the reader, the consignor, etc. The translational eco-environment is a collection of multiple factors that restrict translators' best adaptation and optimized selection. The translator makes the selection with the "identity" of the translational ecoenvironment, and the result of the selection produces the translation. Thus, the translator's adaptation to the translational eco-environment is not equivalent to the passive adaptation of non-human organisms to the natural environment, but an active, selective, creative adaptation. The translator has dynamic "double" status throughout the translation process, and the translator not only undertake the selection and restriction of the translation eco-environment, but also chooses and manipulates the translation as an essential part of the translation ecoenvironment.

\section{THE EFFECT OF MULTIDIMENSIONAL TRANSFORMATION \\ THEORY TO COLLEGE ENGLISH TRANSLATION TEACHING CONSTRUCTION OF ECO-ENVIRONMENT IN COLLEGE \\ TRANSLATION TEACHING}

\section{A. The Emphasis Over the Wholeness of Translational Environment}

The theory of multidimensional transformation in ecotranslatology can effectively promote translation teaching and help improve the translation ability of students. Firstly, ecotranslatology emphasizes the integrity of the translation ecoenvironment. It regards the whole as an organic whole composed of different internal elements of the system, which are interrelated and interact with each other to achieve dynamic balance, promote the overall development and play a role of $1+1>2$. Under the guidance of eco-translatology theory, afterclass and in-class translation teaching complement and interact with each other, providing a convenient and fast platform for students to carry out translation practice anytime and anywhere. Teaching space extends from indoor to outdoor and teaching time from in-class to after-class. The two subsystems complement each other and promote the sound and rapid development of translation teaching as an ecological whole.

\section{B. The Stress and Focus on the Centrality of Translator}

Secondly, eco-translatology emphasizes the translator as the center, occupies a central position and plays a leading role, and is at the interaction point of different languages and cultures. [6]In the process of translation teaching, students are the real translators and the main body and cornerstone of the whole translation process. Translation teaching under the context of eco-translatology emphasizes the interaction between teachers and students, students, students and learning resources, and carries out translation practice at anytime and anywhere, answering questions and solving doubts, sharing information and communicating and evaluating each other. [7]This is conducive to giving full play to students' subjective initiative, taking the initiative to translate, communicate and think, stepping out of the traditional teaching mode and becoming the master of translation study.

\section{The Core Concerns About Selection and Adaptation}

Finally, eco-translatology emphasizes the adaptation and selection of translators. Translators should accept and make selective adaptation to the translation eco-environment, and make adaptive selection after adapting to the translation ecoenvironment. [8] As a translator, when translating each text, students should fully consider the translation eco-environment of the cultural background behind the text and grasp the text from a macro perspective. At the same time, when choosing a translation, the translation strategies used should conform to the three-dimensional translation methods of linguistic dimension, cultural dimension and communicative dimension.

\section{CONCLUSION}

Under the theme of "translation is adaptation and choice", the theory clearly embodies the concept of "translator-centered" in the definition of translation. Translation is "the selection made by the translators to adapt to the translational ecoenvironment". [9] "The translational eco-environment" is the 
"world" presented by the original text, the source language and the translated language, that is, the language, communication, culture, society and the interconnected interaction of authors, readers, and mandator. At the same time, the theory uses the natural law of "survival of the fittest" to propose and demonstrate the translator's central position and the translator's leading role in the translation process, as well as the adaptation mechanism of translator's "self-adaptation" and the restriction mechanism of "ex-post punishment", multidimensional transformation theory plays a promotive role in College English translation teaching, provides a new vision for college students' translation learning.'

\section{REFERENCES}

[1] Bowles M.A. The Think-Aloud Controversy in Second Language Research [M]. New York: Routledge, 2010.
[2] Hatim, B. Teaching and Researching Translation [M]. Edinburgh Gate: Pearson Education Limited, 2001.

[3] Marylin M. Helms, A comparison, Compensation and Benefits Review [J]. 2004, 7-14.

[4] Hu, G. S. Eco-translatology: A New Paradigm of Eco-translation: A Comparative Study on Approaches to Translation Studies and a Brief Response to Some Related Questions/Doubts [J]. Foreign Language of China, 2014(5): 104-111.

[5] Monacelli, C. Self-preservation in Simultaneous Interpreting [M]. Amsterdam: John Benjamins,2009.

[6] Nida, E.A. Language, Culture and Translation [M]. Shanghai : Shanghai Foreign Language Education Press, 1993: 109-110.

[7] Sanz C, Lin H.J., Lado B, Bowden H.W. \& Stafford C.A. Concurrent verbalizations, pedagogical conditions, and reactivity: Two CALL studies [J]. Language Learning, 2009(1):33-71.

[8] Sylwester, S., 2001, R\&D and Economic Growth, Knowledge, Technology, \& Policy, 134,pp.71-84. 45. Tainer E.M., 1998

[9] Wang Jianna, Study on Teaching Mode of English Major Interpretation Under Framework of Eco-translatology [J]. Research in Teaching, 2015(6): 60-63. 